\title{
Investigation of mechanical properties of Armco-iron during fatigue test
}

\author{
A. Vshivkov", A. Prokhorov, S. Uvarov and O. Plekhov
}

\begin{abstract}
Background: In this paper the mechanical properties of armco-iron are studied experimentally. The ultrasonic testing machine USF-2000 was used to carry out fatigue tests involving $10^{6}-10^{10}$ loading cycles. The frequency of loading is $19.5 \pm 0.5 \mathrm{kHz}$. Based on the experimental data, the Wöhler curve was obtained.

Methods: For the analysis of physical condition, two new sensors were designed, one of which measured the electric resistance of the sample and the other measured the magnetic permeability. Second measuring method can be applied to ferromagnetic materials only, though it may be useful for studying the mechanical properties of metals in general.
\end{abstract}

Results: It was shown that the significant changes in physical processes accompanying the evolution of structural defects in the material were observed in the final stages of the experiment.

Conclusions: The applied measurement techniques allowed us to exactly determine the time of fatigue crack initiation below the surface the material, which cannot be monitored by the standard optic methods.

Keywords: Gigacyclic fatigue, Armco-iron, Crack length monitoring

\section{Background}

The necessity of saving resources and improving the economic efficiency of industrial production is a strong impetus for designing new technologies and materials, which could ensure safe fatigue life of various mechanisms and structures such as bridges, railroad tracks, parts of machine and gas turbine engines, and so on, subject to about $10^{10}$ load cycles. The experimental study of fatigue properties of the material on such a cyclic basis involves significant time costs. Nowadays, with the advent of ultrasonic testing machines the researchers can operate with the real-time data and measurements (Bathias \& Gigacycle 2004; Botvina 2004; Plekhov et al. 2005; Shaniavski \& Skvortsov 1999; Zhu et al. 2006).

The characteristic features of the response of the material to giga cyclic fatigue test mode are the initiation of subsurface fatigue cracks and splitting (dual or duplex) of the Weller curve (Naimark et al. 2014; Sakai 2009; Wang et al. 1999). The analysis of published studies suggests that the physical mechanisms underlying these effects are not understood yet. At present, there are several models of this phenomenon, such as the model

\footnotetext{
* Correspondence: vshivkov.a@icmm.ru

Institute of Continuous Media Mechanics UB RAS, Perm, Russia
}

proposed in (Naimark et al. 2000; Plekhov et al. 2007a; Plekhov et al. 2007b).

The development and verification of the proposed models requires a detailed experimental study of the process of defect evolution in the material at the final stage of cyclic deformation with small amplitudes of load. The study on structural evolution of armco-iron was done in (Wang et al. 2012). Here it has been shown that in the region of gigacyclic fatigue, the cyclic deformation of pure iron can lead both to the formation of a stable shear band on the sample surface (by analogy with copper or nickel), and characteristic subsurface structures of the "fish eye" type.

These structural studies require interruption of fatigue experiment and therefore cannot give information on the kinetics of the critical defect evolution leading to the destruction of the macroscopic sample. In this paper, our primary concern was to develop an experimental methodology for detecting processes that accompany the evolution of defects in the material during fatigue test on the ultrasonic testing machine.

The mechanical properties of the sample were determined during tests on servo-hydraulic testing machine INSTRON 8500E. The fatigue test was carried out on the ultrasonic testing machine USF-2000 at loading frequency of $20 \mathrm{kHz}$. As a result, the mechanical characteristics of

\section{纹 Springer}

(C) 2016 Vshivkov et al. Open Access This article is distributed under the terms of the Creative Commons Attribution 4.0 International License (http://creativecommons.org/licenses/by/4.0/), which permits unrestricted use, distribution, and reproduction in any medium, provided you give appropriate credit to the original author(s) and the source, provide a link to the Creative Commons license, and indicate if changes were made. 
the material were estimated during quasi-static loading and fatigue properties were determined on the basis of tests including up to $10^{10}$ loading cycles.

The magnetic method and the method of measuring the potential drop were used as the most appropriate instruments for studying the kinetics of defect propagation, because they allowed us to record both the appearance of surface and subsurface cracks. The methods have been significantly modified to be able to use the non-linear effects that increase their sensitivity threshold. The obtained data support the view that recording of kinetics of subsurface crack evolution is possible and confirm the hypothesis for the intensive propagation of such cracks at the final stage of the deformation process.

\section{Material and experimental conditions}

The experiment was carried out using samples of armco-iron. The chemical composition of samples is shown in Table 1. It investigated the mechanical behavior of the cylindrical samples, $4 \mathrm{~mm}$ thick, whose geometry is shown in the Fig. 1.

Two series of samples have been investigated to ensure reliability of the obtained results. These series were made from the same batch of armco-iron, which were subject to the same mechanical and thermal treatment. The first series of samples was tested on the servohydraulic tensile machine INSTRON 8500, and the second series was tested on the electromechanical tensile machine Zwick 100. The samples were subject to uniaxial tensile loads at the strain rate varying from $10^{-4} \mathrm{~s}^{-1}$ to $2 \cdot 10^{-3} \mathrm{~s}^{-1}$ with small strain conditions calculated as $\Delta \mathrm{l} / \mathrm{l}$, where 1 is gauge part of the specimen. The results of mechanical testing are presented in the Fig. 2.

The second cyclic test was carried out using the Shimadzu USF-2000 ultrasonic testing machine, which delivers accelerated testing of the fatigue properties of materials at $20 \mathrm{kHz}$. The $20 \mathrm{kHz}$ vibration generated by the piezo element is amplified by the booster and the horn and transmitted to the sample to generate repeated stress. In the ultrasonic fatigue testing system, the vibration system is constructed so that the longitudinal waves transmitted through the solid body resonate. Consequently, stationary longitudinal waves are formed inside the vibration system (sample, horn and booster). From the physical point of view, the mass of the sample itself plays the role of a generating reactive force, and there is no need to immobilize one side of the sample. By measuring the displacement of a free side of the sample, the generated strain distribution into the sample can be calculated. The uniform stress testing

Table 1 The chemical composition of the armco-iron

\begin{tabular}{lllllllll}
\hline Fe $\%$ & $\mathrm{C} \%$ & $\mathrm{Mn} \%$ & $\mathrm{Si} \%$ & $\mathrm{~S} \%$ & $\mathrm{P} \%$ & $\mathrm{Ni} \%$ & $\mathrm{Cr} \%$ & $\mathrm{Mo} \%$ \\
\hline 99.788 & 0.004 & 0.04 & 0.05 & 0.005 & 0.005 & 0.06 & 0.038 & 0.01 \\
\hline
\end{tabular}

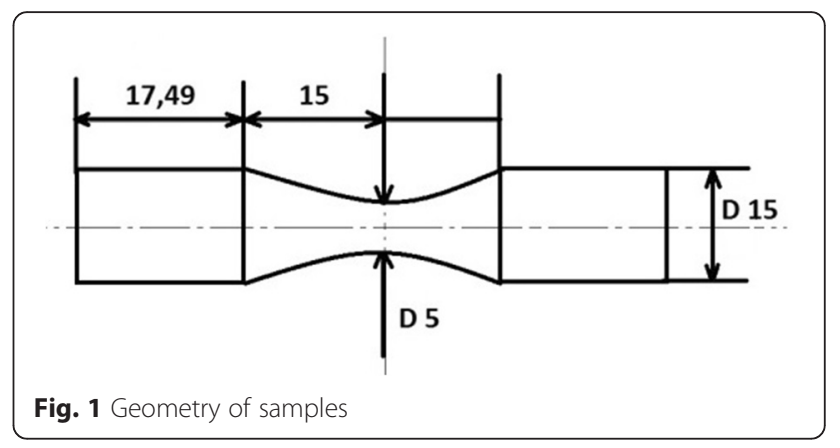

can be carried out by controlling the amplitude of the vibration. The application of ultrasonic testing machines for fatigue experiments are described in (Bathias \& Gigacycle 2004; Bathias \& Paris 2005; Palin-Luc et al. 2010).

In the present study, all the samples were tested at the constant stress amplitude up to the failure. The cooling of the sample was realized by an air stream. The temperature of the sample was controlled by infrared camera. The ordinary temperature rise during the stable test regime was about 50C. The experiment lasted until the resonance frequency of the sample changed significantly (by more than $10 \%$ ).

During the experiments an infrared camera Flir SC 5000 (spectral range of 3-5 $\mu$, the temperature sensitivity of $0.25 \mathrm{~K}$ ) was used to control the temperature of the sample. The standard calibration table for $1000 \mathrm{~ms}$ exposure time was applied to calibrate the unit.

\section{Methods}

In the magnetic method the ferromagnetic properties of the material is used to monitor processes that accompany the evolution of the material structure. This technique is a modification of the non-destructive ferroprobe testing method. In this case, the sample is simultaneously the object of study and the core of a ferroprobe. In this method, the parameter to be measured is magnetic permeability, because it changes at the time of defect nucleation. The experimental setup is shown in the Fig. 3.

During the experiment, two electromagnetic coils were placed on the sample: the magnetizing coil (diameter of copper wire is $0.5 \mathrm{~mm}$., 800 turns) and measuring coil (diameter of copper wire is $0.1 \mathrm{~mm}$., 200 turns). The alternating current in the magnetizing coil magnetized the sample to saturation. This point was fixed by the appearance of the nonlinear useful signal in the measuring coil. It was found that the second harmonic of the measuring coil signal was most sensitive to the magnetic field variation inside the sample (inductance of sample).

To switch the magnetizing coil, a mini amplifier of signals was assembled based on the TDA2030a chip (18 W $\mathrm{HiFi}$ power amplifier class $\mathrm{AB}$ ). This amplifier provides high output current, has small harmonic and intermodulation distortions, wide bandwidth of the amplified 


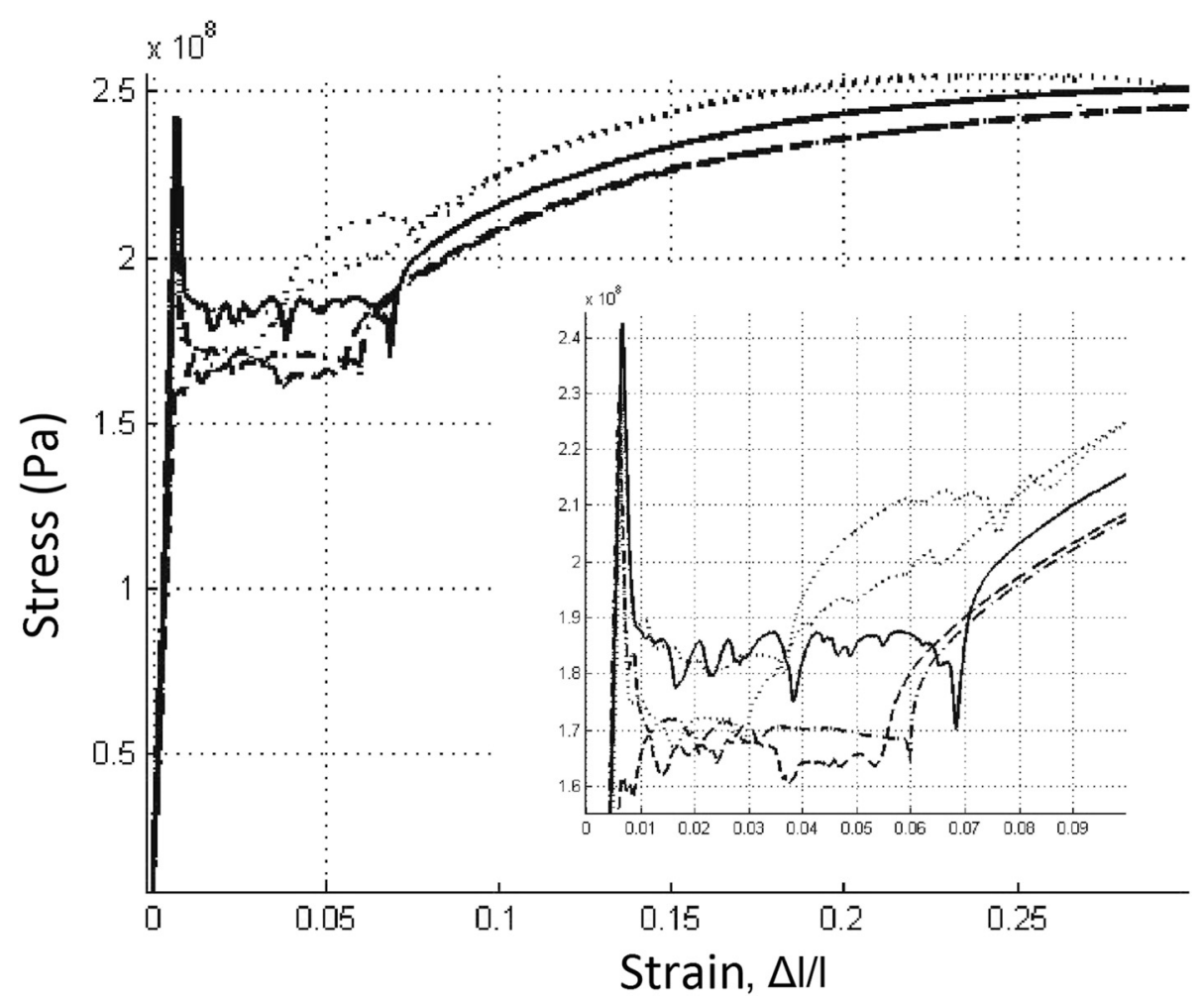

Fig. 2 The stress-strain curve for the armco-iron at different strain rates (dotted lines is the strain rate $10^{-4} \mathrm{~s}^{-1}$, solid line is the strain rate $10^{-3} \mathrm{~s}^{-1}$, dashed lines is the strain rate $2 \cdot 10^{-3} \mathrm{~s}^{-1}$ )

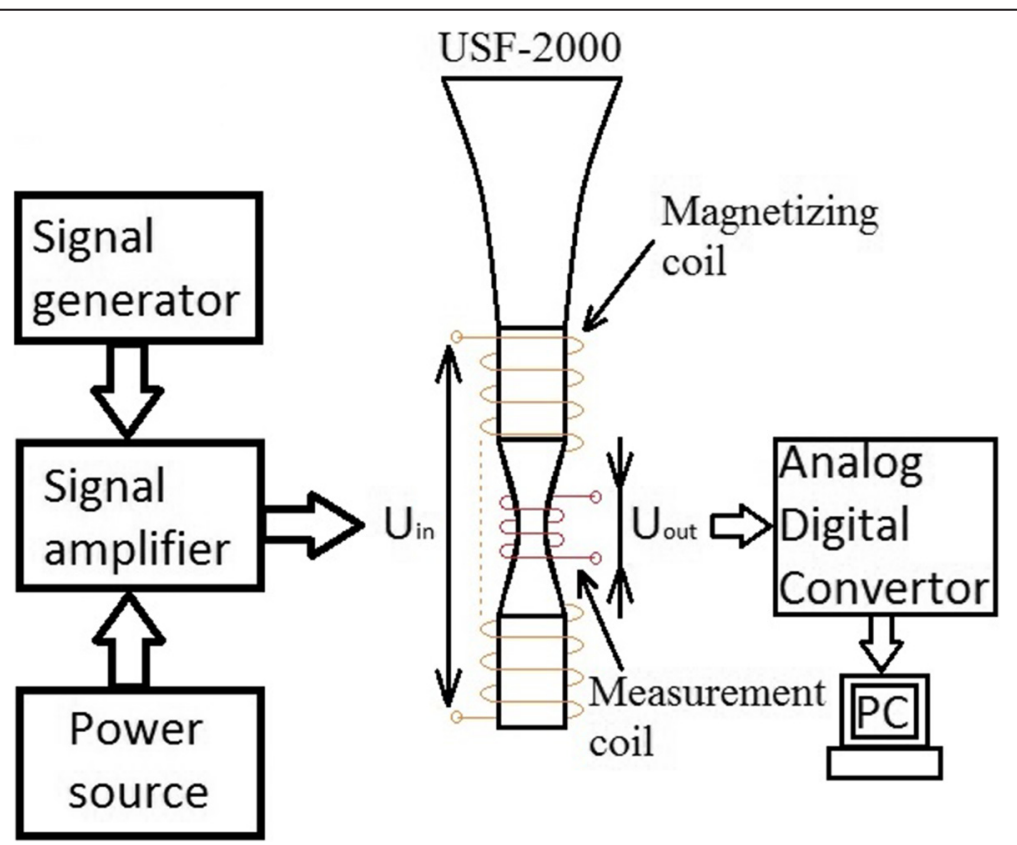

Fig. 3 Schematic diagram of the installation of the magnetic method of the registration evolution of the material structure during fatigue testing (refer to the diagram: Function generators AKIP3407/1A power supply AIP B5.120/0.75, ultrasonic testing machine USF-2000) 
signal, low level of intrinsic noise, the built-in protection against the output short circuit, automatic system to limit dissipated power, which holds the working point of the output transistors in the safe area. The built-in thermal protection element switches off the chip when the crystal is heated above $145{ }^{\circ} \mathrm{C}$. The chip is produced in the Pentawatt package and has five pins.

The magnetizing coil can operate in two modes: stabilization of voltage and stabilization of current. The analog-digital convertor (ADC) NI is used to register the measuring coil signals. The instrument accuracy of the measurement voltage by ADC is $6 \mathrm{uV}$. The measurement data is analyzed in real time using the LabVIEW software package.

An alternative method of monitoring the nucleation of the fatigue crack is the method of controlling the voltage drop (four-point measurement of the electrical resistance). In this method four contacts are placed on the sample, which is set fixed inside the ultrasonic testing machine. A pair of external contacts is used for supplying DC current of $5 \mathrm{~A}$ to the specimen. A pair of the internal contacts is used to register the potential drop in the specimen. In addition, ADC NI is used to measure potential drop. Schematic diagram of the method is shown in the Fig. 4. The instrument accuracy of the electrical resistance is $30 \mathrm{u} \Omega$.

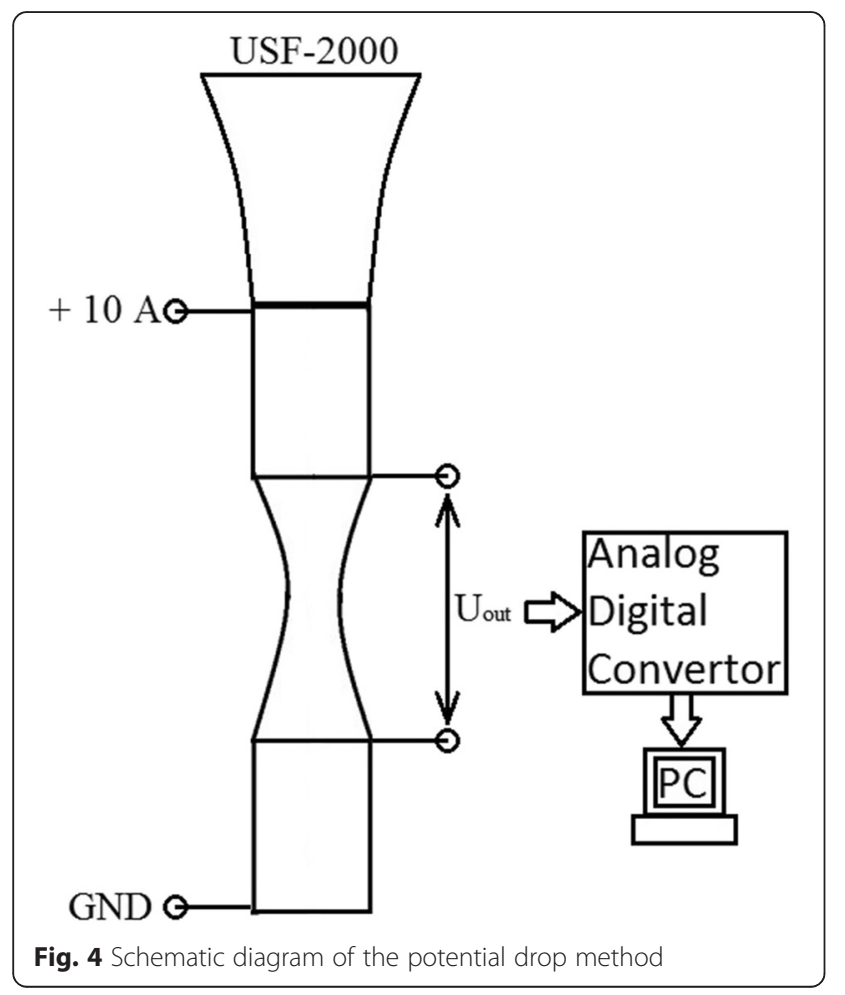

\section{Results and discussion}

The Fig. 5 shows the results of testing 11 specimens of armco-iron on the ultrasonic testing machine USF-2000 at loading frequency of $20 \pm 5 \mathrm{kHz}$. The analysis of the data presented in the Fig. 5 leads us to the conclusion that for the examined material the fatigue limit obtained on the basis of $3 \cdot 10^{9}$ loading cycles is $160 \mathrm{MPa}$.

It should be noted that the armco-iron specimens under tensile loading demonstrate abnormal deformation behavior. According to literature (Plekhov et al. 2005), a decrease in the resonant frequency during the fatigue test on ultrasound machine is an irreversible process and corresponds to the emergence of a subsurface fatigue crack. In the case of armco-iron, the decay of the resonance frequency did not imply mechanical (macroscopic) destruction of the specimen after stopping the testing machine.

The specimens withstood practically unlimited number of subsequent runs during $10^{6}$ loading cycles. An increase of the dwell time between successive runs allowed us to slightly increase the duration of one test run to $2 \cdot 10^{6}$ cycles. The Fig. 10 shows the results of using the potential drop method in the process of specimen loading in series of $10^{6}$ cycles after its coming out of the resonance frequency range during the main test.

Such a behavior of the specimens suggests the presence of irreversible changes in the structure of the material, which can be critical for endurance limit of the specimen during ultrasonic loading tests. At the same time, these changes are not related to the formation of fatigue cracks and are indicative of a sharp increase in the dissipation ability of the specimen and impossibility of further specimen testing in the tensile test machine provided with a standard (air) cooling system. In the Fig. 5, the graph is plotted assuming that this state of the specimen corresponds to its fracture.

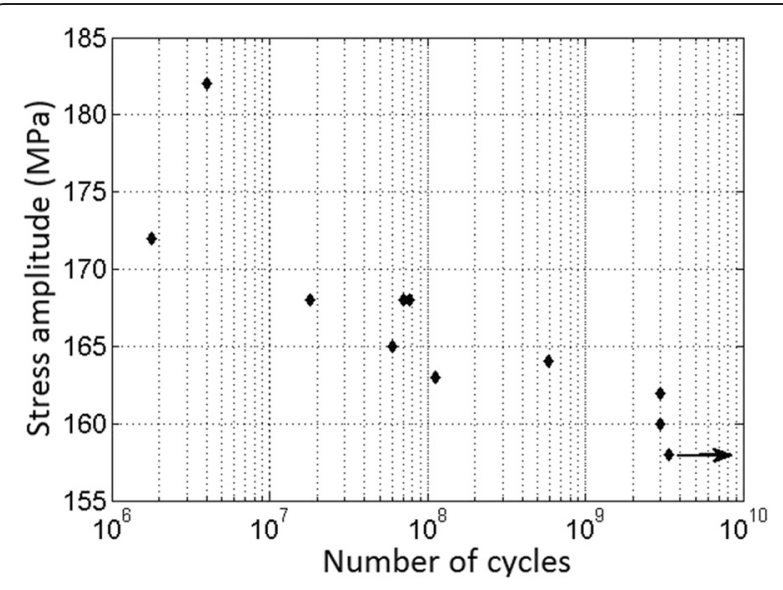

Fig. 5 Wöhler curve for armco-iron 
Measurements of the temperature of the specimen during tests showed that in the final stage of the process there is a sharp increase of the specimen temperature (about $200{ }^{\circ} \mathrm{C}$, Fig. 6), that accompanied by a decrease of the resonance frequency.

Two test programs were realized to investigate changes in magnetic permeability and electrical resistance of the specimen. Within the first program the specimens were tested to failure (overheating), and within the second program the specimens were subject to stepwise loading sets with increasingly growing amplitudes.

A typical graph of the second harmonic amplitude of the measuring solenoid obtained in the framework of the first testing program is shown in the Fig. 7. The amplitude of the second harmonic increases significantly as a result of the magnetic saturation of the specimen due to changes in the magnetic permeability after $9 \cdot 10^{8}$ cycles of loading. The change of the magnetic permeability can be caused by a number of physical processes, such as dispersive accumulation of defects, formation of the fatigue crack, or overheating of the specimen, which reduces its resistance. According to the data of the magnetic method the fast increase of the second harmonic amplitude of the magnetic field happened in final stage of test.

When loading was carried out with the amplitude higher than that of fatigue limit, the process proceeded at a higher rate (Fig. 8). The amplitude of the second harmonic of the magnetic field during experiment began to increase and after approximately $60 \mathrm{~s}\left(1.2 \cdot 10^{6}\right.$ loading cycles) the process progressed in an avalanche fashion and after $20 \mathrm{~s}\left(4 \cdot 10^{5}\right.$ cycles $)$ the resonance frequency changes.

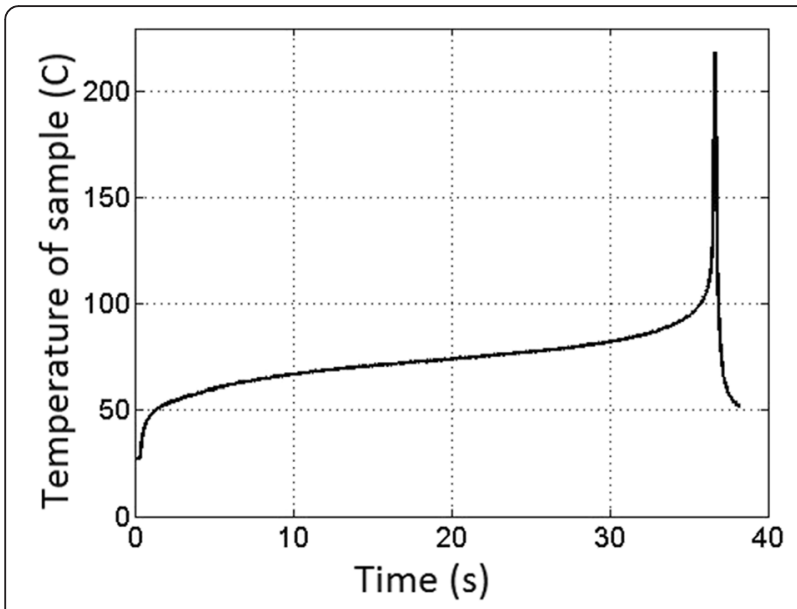

Fig. 6 Temperature of sample in the final stage of fatigue test

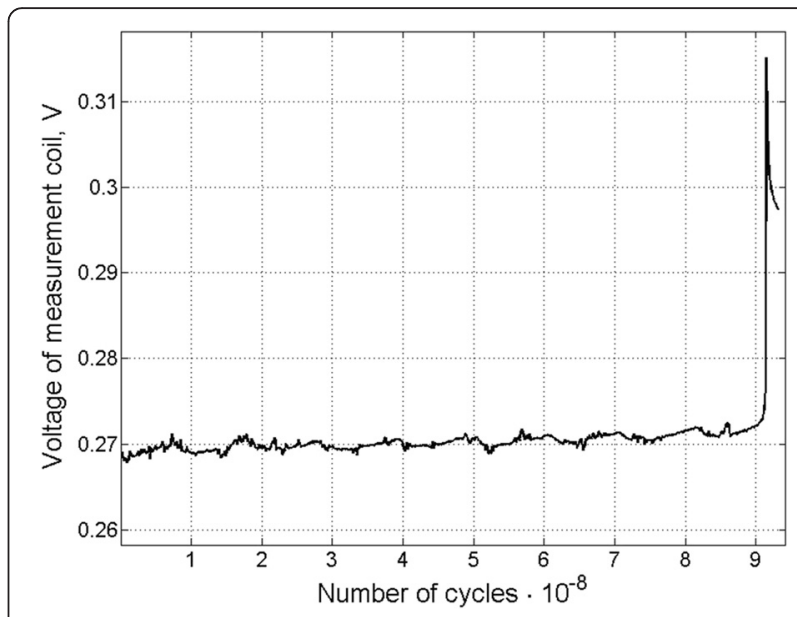

Fig. 7 The change of the second harmonic amplitude of the electric voltage on the measurement solenoid during fatigue test with stress $160 \mathrm{MPa}$

Similar results were obtained using the potential drop method. The Fig. 9 shows the electrical resistance of the specimen at the final stage of the experiment with the amplitude of stress of $258 \mathrm{MPa}$.

The results of cyclic loading of specimens are shown in the Fig. 10. It should be noted that the developed methods could not be applied simultaneously to one and the same specimen. For this reason, in the Fig. 10 the results of two different tests are compared.

The Fig. 10a presents seven loading runs performed at different amplitudes of mechanical stress (from 198 to $258 \mathrm{MPa}$ ). By virtue of the structural features the magnetic method data were recorded in the form of a single array (Fig. 10b). The valleys on the curve correspond to the moments when the testing machine was stopped and

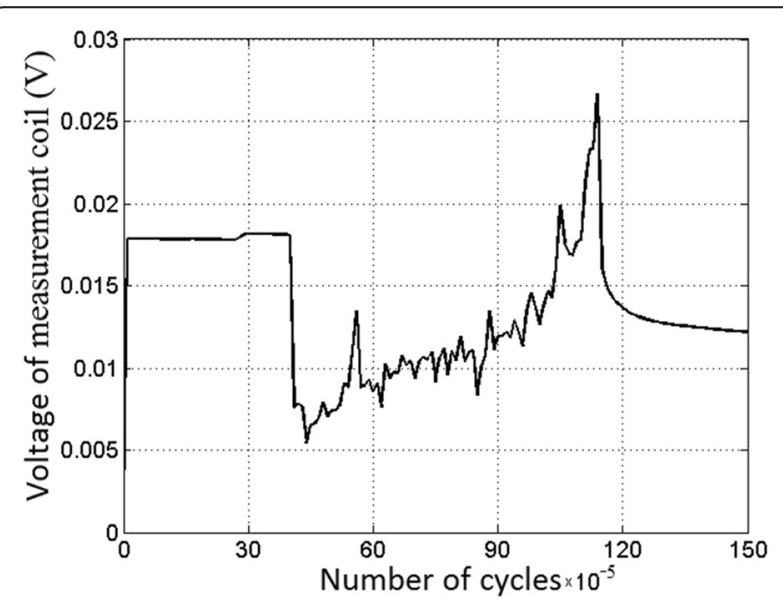

Fig. 8 The change of the second harmonic amplitude of the electric voltage on the measurement solenoid during fatigue test with stress $165 \mathrm{MPa}$ 


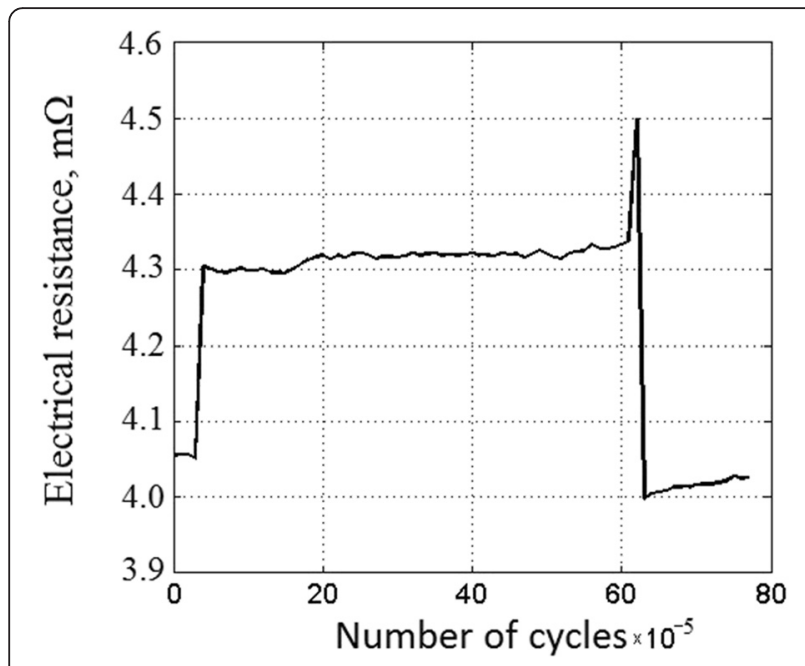

Fig. 9 The electrical resistance of the sample during fatigue test with stress $258 \mathrm{MPa}$

the specimen was prepared for the next run of loading at higher amplitudes.

For small amplitudes of stress both measurement methods provided signals with constant amplitude (Fig. 10a and the first segment of the curve in Fig. 10b.). An increase in the stress amplitude leads to an increase of the electric resistance in the specimen and a decrease in the second harmonic amplitude of the measuring coil voltage. At sufficiently high mechanical stresses the data obtained by both methods demonstrate abrupt jumps, which correspond to the destruction (overheating) of the specimen.

\section{Conclusion}

We have investigated experimentally the mechanical behavior of armco-iron under conditions of giga cycle fatigue loading. The experiments were carried out on the ultrasonic testing machine USF-2000 with loading frequency $20 \mathrm{kHz}$ and air cooling. Based on the results of tests comprising $10^{10}$ cycles the Weller curve for the examined material has been plotted. The value of the fatigue limit is $160 \mathrm{MPa}$.

The experiments have shown that armco-iron reaches its fatigue limit in the abnormal manner. A decrease of the resonance frequency was accompanied by strong (up to $220^{\circ} \mathrm{C}$ ) heating of the specimen. However, on the surface of the specimen the formation of structural defects has been not observed even with a standard metallographic microscope. In repeated tests, overheating of the specimen occurred after performing $10^{6}$ loading cycles.

Two new systems for monitoring the physical properties of the specimens have been developed for studying the process of fatigue crack nucleation. These systems are based on the measurement of the electric resistance and induction of the magnetic field. It has been shown that a significant change in the physical processes accompanying the evolution of structural defects in the material is observed at the final stages of the experiment.

The preliminary experiments clearly demonstrated that these methods can be used to monitor the processes of evolution of the material structure during fatigue tests on the ultrasonic testing machine and to estimate the duration of the final stage, at which the specimen reaches its endurance limit. For small amplitudes of the applied stress, the significant changes of parameters are observed during the final $3 \cdot 10^{6}$ loading cycles. In this case the catastrophic changes leading to heating of the sample up to $200^{\circ} \mathrm{C}$. lasted during $10^{5}$ loading cycles.

An exhaustive reply to the question, as to what changes in the structure of the material lead to an increase in its dissipation ability, requires intensive structural studies.

The reported study was funded by RFBR according to the research project No. 16-31-00155 мо __a and No. 14-01-00122.
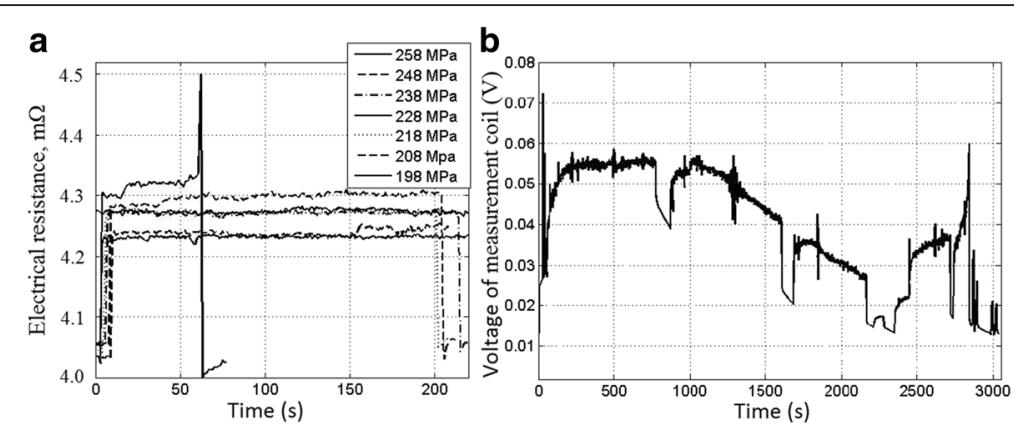

Fig. 10 The electrical resistance of the sample $\mathbf{a}$ and the second harmonic of the voltage $\mathbf{b}$ by the magnetic methods during blocks loading of the sample 


\section{About the authors}

Aleksey Vshivkov (Perm, Russia)-Ph.D. student of Institute of Continuous Media Mechanics Russian Academy of Sciences Ural Branch (614013, 1, Ak. Koroleva, Perm, Russia, e-mail: vshivkov.a@icmm.ru).

Alexander Prokhorov (Perm, Russia)—Ph.D. student of Institute of Continuous Media Mechanics Russian Academy of Sciences Ural Branch (614013, 1, Ak. Koroleva, Perm, Russia, e-mail: prokhorov.a@icmm.ru).

Sergey Uvarov (Perm, Russia)—Ph.D., senior researcher director of Institute of Continuous Media Mechanics Russian Academy of Sciences Ural Branch (614013, 1, Ak. Koroleva, Perm, Russia, e-mail: usv@icmm.ru)

Oleg Plekhov (Perm, Russia)—Doctor of Physical and Mathematical Sciences, Deputy director of Institute of Continuous Media Mechanics Russian Academy of Sciences Ural Branch (614013, 1, Ak. Koroleva, Perm, Russia, email: poa@icmm.ru)

\section{Competing interests}

The authors declare that they have no competing interests.

\section{Authors' contribution}

AV carried out experiments with magnetic method, participated in the sequence alignment and drafted the manuscript. AP carried out experiments with electric method. SU have been involved in revising it critically for important intellectual content and realized technical support during experiments. OP participated in study design and coordination and helped to draft the manuscript. All authors read and approved the final manuscript.

Received: 2 September 2015 Accepted: 22 February 2016

Published online: 25 March 2016

\section{References}

Bathias C, Paris P (2004) Gigacycle Fatigue in Mechanical Practice. Taylor \& Francis, New York, p 328

Bathias C, Paris PC (2005) Gigacycle fatigue in mechanical practice. Marcel Dekker Publisher Co, New York USA

Botvina L (2004) Gigaciklovaya ystalost-novaya problema fiziki I mehaniki razrysheniya. Plants laboratory. Materials diagnostic 70(4):41-51

Naimark OB, Davydova M, Plekhov OA, Uvarov SV (2000) Nonlinear and structural aspects of transitions from damage to fracture in composites and structures. Comput Struct 76(1):67-75

Naimark O, Plekhov O, Betekhtin V, Kadomcev A, Narikova M (2014) Kinetika nakopleniya defektov I dyalnost Krivoi vellera pri gigaciklovoi ystalosti metallov. TPJ 84(3):89-94

Palin-Luc T, Perez-Mora R, Bathias C, Dominguez G, Paris PC, Arana UL (2010) Fatigue crack initiation and growth on a steel in the very high cycle fatigue regime with sea water corrosion. Eng Fract Mech 77:1953-1962

Plekhov OA, Naimark O, Saintier N (2007a) Experimental study of energy accumulation and dissipation in iron in an elastic-plastic transition. Technical physics. The Russian Journal of Applied Physics 52(9):1236-1238

Plekhov O, Palin-Luc T, Naimark O, Uvarov S, Saintier N (2005) Fatigue crack initiation and growth in a 35CrMo4 steel investigated by infrared thermography. Fatigue fract eng mater struct 28(1):169-178

Plekhov O, Saintier N, Palin-Luc T, Uvarov S, Naimark O (2007b) Theoretical analysis, infrared and structural investigation of energy dissipation in metals under quasi-static and cyclic loading. Mater Sci Eng 462(1):367-370

Sakai T (2009) Review and prospects for current studies on very high cyclic fatigue of metallic materials for machine structural use. Journal of solid mechanics and materials engineering 3(3):425-439

Shaniavski AA, Skvortsov GV (1999) Fatigue limit-material property as an opened or closed system (1999) practical view on the aircraft components failures in GCF area. Fatigue Fract Eng Mater Struct 22(7):609-619

Wang OY, Berard JY, Rathery S, Bathias C (1999) Technical note high-cycle fatigue crack initiation and propagation behaviour of high-strength sprin steel wires. Fatigue Fract Eng Mater Struct 22:673-677

Wang C, Wagner D, Wang QY, Bathias C (2012) Gigacycle fatigue initiation mechanism in Armco iron. Int J Fatigue 45:91-97

Zhu X, Shyam A, Jones JW, Mayer H, Lasecki JV (2006) Allison JE effects of microstructure and temperature on fatigue behavior of E319-T7 cast aluminum alloy in very long life cycles. Int J Fatigue 28:1566-1571

\section{Submit your manuscript to a SpringerOpen ${ }^{\circ}$ journal and benefit from:}

- Convenient online submission

- Rigorous peer review

- Immediate publication on acceptance

- Open access: articles freely available online

- High visibility within the field

Retaining the copyright to your article 